\title{
OS MOVIMENTOS SOCIAIS GLOBAIS E A DEMOCRACIA PARTICIPATIVA: UM OLHAR NO "PODER PARA" NA SOCIEDADE INTERNACIONAL CONTEMPORÂNEA
}

\author{
Isadora K. Lazaretti* \\ Giovanni Olsson **
}

\section{RESUMO}

O presente artigo tem como objetivo compreender o poder dos movimentos sociais globais na democracia participativa na sociedade internacional contemporânea. Os movimentos sociais globais são atores coletivos que exercem poder sem intermediários por conta de seu relevante potencial reformador, uma vez que, por meio de suas lutas, protestos, manifestações e mobilizações, pressionam e participam de forma direta das decisões dos Estados. Com isso, constituem a expressão da democracia participativa, que configura a forma mais autêntica de democracia do século XXI. A metodologia utilizada tem por base a abordagem qualitativa e o método dedutivo, adotando-se a técnica de pesquisa bibliográfica.

Palavras-chave: movimentos sociais globais; democracia participativa; poder; sociedade internacional; globalização.

\section{GLOBAL SOCIAL MOVEMENTS AND PARTICIPATORY DEMOCRACY: A LOOK AT "POWER TO" IN CONTEMPORARY INTERNATIONAL SOCIETY}

\begin{abstract}
This article aims to understand the power of global social movements in participatory democracy in contemporary international society. Global social movements are collective actors that exercise power without intermediaries because of their relevant changing potential, since, through their struggles, protests, demonstrations, and mobilizations, they push and participate directly in the decisions of the States. This is the expression of participatory democracy, which is the most authentic form of democracy in the 21 st century. The methodology used is based on the qualitative approach and the deductive method, adopting the technique of bibliographic research.
\end{abstract}

Keywords: global social movements; participatory democracy; power; international society, globalization.

\section{INTRODUÇÃO}

\footnotetext{
*Mestre em Direito pela Universidade Comunitária da Região de Chapecó - Unochapecó. Pesquisadora do Grupo de Pesquisa em Relações Internacionais, Direito e Poder da Unochapecó. E-mail: isadoralazaretti@unochapeco.edu.br

*** Doutor em Direito pela Universidade Federal de Santa Catarina. Professor do Programa de Mestrado em Direito da Universidade Comunitária da Região de Chapecó - Unochapecó. E-mail: golsson71@ gmail.com
} 
O presente artigo versa sobre o "poder para" dos movimentos sociais globais na democracia participativa da sociedade internacional contemporânea. A opção pela temática e sua problematização encontra fundamento na complexidade e relevância, uma vez que há, atualmente, uma reconfiguração do poder no cenário internacional, que se expressa pelo protagonismo dos novos atores internacionais, a exemplo dos movimentos sociais, que, nesse caso, atuam a ponto de refletir na própria democracia dos Estados.

O objetivo geral desta pesquisa consiste em compreender o poder dos movimentos sociais globais na democracia participativa na sociedade internacional contemporânea. Especificamente, busca-se estudar os movimentos sociais como atores não-estatais emergentes; analisar a crise da democracia contemporânea; entender o "poder para" como categoria instrumental; e, por fim, investigar as possibilidades dos movimentos sociais globais na (re)democratização contemporânea.

O estudo do poder dos movimentos sociais globais é um tema contemporâneo, de modo que o objeto de pesquisa por si só se mostra interessante pelo destacado protagonismo exercido pelos movimentos sociais globais em nível mundial. A investigação dessa problemática acarreta uma provocação nos modelos pré-estabelecidos até então intactos.

Dessa forma, num primeiro momento, a presente pesquisa abordará os movimentos sociais globais enquanto atores não-estatais emergentes na sociedade internacional globalizada. Na sequência, necessário estudar o conceito de democracia, as suas formas e as dificuldades que se manifestam atualmente e formam a crise da democracia contemporânea. Em seguida, o presente trabalho direciona-se ao estudo do poder enquanto categoria instrumental e sua classificação tradicional em "poder para" e "poder sobre". Por fim, serão analisadas as possibilidades do exercício do "poder para" pelos movimentos sociais globais na (re)democratização contemporânea.

Quanto à metodologia, adota-se na presente pesquisa o método dedutivo. Quanto ao método de procedimento, utiliza-se o método de procedimento histórico e o método estruturalista, partindo da investigação dos movimentos sociais no cenário global como um fenômeno concreto que representa o objeto de estudo da pesquisa. A pesquisa tem caráter qualitativo, e a técnica de pesquisa utilizada foi a bibliográfica. 


\section{OS MOVIMENTOS SOCIAIS COMO ATORES NÃO-ESTATAIS EMERGENTES}

A sociedade internacional passou a se modelar enquanto uma sociedade tipicamente interestatal a partir da instituição do Estado Moderno, que se firmou após um longo e demorado período histórico, que teve como ponto central diversos acontecimentos políticos que conduziram à transição da Idade Média para o mundo moderno. Com o Estado centralizado e sua soberania instituída, tanto interna quanto externamente, o Estado passou a ser o núcleo fundamental das articulações políticas da história humana, ensejando o surgimento da sociedade internacional moderna (BEDIN, 2001, p. 167).

A sociedade internacional pode ser compreendida como "um conjunto de relações sociais e interdependentes, que constituem um todo" (ARENAL, 1979, p. 430). Truyol y Serra notam que a sociedade internacional é uma "sociedade humana considerada sob certos aspectos" (1998, p. 26). A compreensão da sociedade internacional contemporânea reflete na modernização do mundo. O fenômeno da globalização contribuiu expressivamente para sua formação e transformação. Nesse viés, a partir da década de 1970, o cenário internacional passou a se alterar de forma gradativa, por conta do intenso desenvolvimento tecnológico nas áreas da comunicação, transportes e da informática. A economia foi assolada por mudanças consideráveis, que redefiniram inclusive a política e a sociedade.

A globalização é entendida por Arnaud (1999, p. 16) como o "[...] processo social, econômico, cultural e demográfico que se instala no coração das nações e as transcende ao mesmo tempo, de tal forma que a atenção limitada aos processos locais, às identidades locais, às unidades de análise locais, torna incompleta a compreensão do local”.

Diante das transformações que se verificaram no cenário mundial, emergiu a noção de que as distâncias parecem ter diminuído e o tempo parece andar mais rápido. Verifica-se, assim, uma verdadeira "aceleração de mundo", uma vez que atravessar continentes não mais exigia dias de viagem, ao mesmo tempo que também se tornou possível o contato com indivíduos de qualquer lugar do mundo em tempo real. Mais além, a circulação de bens tornou-se constante entre os países do globo (HALL, 1999, p.69-72).

Essa realidade passou a se intensificar a partir da década de 1970, quando os avanços tecnológicos nos meios de comunicação, transportes e na informática proporcionaram os meios para a expansão dos mercados financeiros e a intensificação irrefreável do capitalismo, ocasionando uma circulação financeira internacional de bens e serviços além dos recortes 
nacionais. Essa ampliação assustadora da chamada "especulação financeira" constitui um resultado direto das novas tecnologias, uma vez que a integração dos espaços mundiais de comunicação, com satélites e fibras óticas, e a rapidez no processamento e armazenamento de dados, levaram a grandes avanços em termos de globalização (DOWBOR, 2002, p. 29).

A globalização causou consequências não apenas para a esfera da economia, mas também à política e ao Estado moderno. Com o aumento das interconexões globais, a soberania do Estado que, até então, mantinha-se absoluta e intacta, passou a ser desafiada. O Estado tem suas autonomia e soberania enfraquecidas por conta da emergência dessa nova era globalizada de fluxos entre e essencialmente além das nações. Em verdade, o Estado de modelo nacional não desapareceu, mas perdeu forças para regular e controlar seus próprios assuntos domésticos.

Nesse sentido, “[...] por um lado, o Estado já não pode mais querer regular a sociedade civil nacional por meio de seus instrumentos jurídicos tradicionais, dada a crescente redução de seu poder de intervenção, controle, direção e indução [...]”, e, ainda, que, por outro lado, o Estado "[...] é obrigado a compartilhar sua soberania com outras forças que transcendem o nível nacional” (BEDIN, 2001, p. 349).

Essas forças são, especificamente, os novos atores internacionais que emergiram na sociedade internacional, fazendo com que o Estado deixasse de ser o único centro de poder desse espaço, como se mantinha no paradigma do realismo político. A partir da interdependência, constituiu-se uma imensa aldeia global (McLUHAN, 2001), marcada pela tecnologia em larga escala, pela velocidade dos fluxos, pelas redes complexas, pela praticidade de armazenamento de dados e pelas interconexões virtuais em nível global. Essa nova realidade fez com que novas figuras no cenário internacional protagonizassem esse cenário, concorrendo, inclusive, com a figura do Estado (OLIVEIRA, 1999, p. 55).

Associada a outros fatores conjunturais, a globalização foi decisiva para o surgimento de uma ampla gama de atores internacionais, fazendo com que as relações internacionais passassem a ser analisadas a partir de uma nova esfera de interações transnacionais em um mundo crescentemente interdependente (REYNALDO, 2016, p. 21).

Nesse viés, o conceito de ator internacional pode ser compreendido a partir dos estudos realizados por Oliveira (2014, p. 97), que o define como “[...] o agente que participa das relações internacionais, desempenha o próprio ato internacional, atua na dimensão dinâmica da sociedade internacional, formada por um elenco de agentes sociais". 
Barbé (1995, p.117), por sua vez, considera os atores internacionais como uma “[...] unidade do sistema internacional (entidade, grupo, indivíduo) que tem a habilidade para mobilizar recursos que lhe permitem alcançar seus objetivos e capacidade para exercer influência sobre outros atores do sistema e que goza de certa autonomia".

A principal característica dos atores internacionais é que eles ultrapassam as fronteiras estatais, criando redes de ação que se encontram subsidiadas de forma destacada no cenário global. Além disso, os atores internacionais são libertados do controle restritivo do ente estatal. Como exemplos desses atores, encontram-se as organizações internacionais, as empresas transnacionais, a mídia, os indivíduos detentores de poder e posição de comando, organizações sociais, movimentos sociais, governos não centrais, crime organizado e tantos outros em elencos ainda controversos (BRANDL; DE FAZIO, 2015, p. 230).

No que diz respeito à classificação desses atores, Marcel Merle (1981, p. 213) entende que eles se dividem em três categorias: os Estados, considerados como atores estatocêntricos, detentores do poder de decisão e força de coerção; as Organizações Internacionais, que, com autonomia e independência, desempenham papéis específicos e determinados; e, por fim, as Forças Transnacionais, que se dividem em Empresas Transnacionais, Organizações Não-Governamentais e a opinião pública internacional.

Oliveira (2014, p. 101-102), por sua vez, apresenta a tipologia dos atores internacionais a partir de um parâmetro eclético, que abrange os atores tradicionais, que compreendem os Estados e seus desdobramentos estatocêntricos; os novos atores, que abrangem as organizações internacionais, organizações não-governamentais e empresas transnacionais; e os atores emergentes, que abrangem representantes dos tempos contemporâneos, como os movimentos sociais globais, grupos privados, indivíduos, governos não centrais, opinião pública, partidos políticos, mídia, sindicatos, terrorismo e gênero, dentre outros.

Com a globalização, e diante do surgimento de uma gama de atores internacionais, destacam-se, neste trabalho, os movimentos sociais, que passaram a se organizar em rede e de forma transnacionalizada, intensificada e consolidada a partir do início do século $\mathrm{XX}$ (REYNALDO, 2016, p. 261).

Os diversos movimentos que surgiram em todo o mundo se originaram, especialmente, na crise econômica e na crise de legitimidade que se tornou cada vez mais profunda. A crise global de produção de alimentos, por exemplo, impactou na subsistência de 
milhares de pessoas, especialmente nos países árabes, quando os preços dos alimentos alcançaram níveis altíssimos. Contudo, os movimentos sociais não emergem apenas da pobreza ou de crises políticas. Seu surgimento também está vinculado à exigência de “[...] uma mobilização emocional desencadeada pela indignação que a injustiça gritante provoca, assim como pela esperança de uma possível mudança em função de exemplos de revoltas exitosas em outras partes do mundo" (CASTELLS, 2013, p. 163).

Os movimentos sociais apresentam fluxos e refluxos na realidade, e constituem um campo de ação social coletiva que se manifesta atualmente não somente em nível local, uma vez que, por conta do fenômeno globalizante, o protagonismo desses atores atinge inclusive o nível global (GOHN, 2003, p. 8). Trata-se, assim, de importantes atores que ostentam caráter fundamental. Objetivam mudanças dentro de determinados setores da sociedade, porque "são em si manifestações de mudança social” (MATTAR, 2013, p. 116). Esses grupos possuem uma estrutura distinta, e são formados por atores, lutas e ações coletivas.

No âmbito internacional, os movimentos sociais alteram completamente sua posição, porque se redefinem, e somente os de caráter mais global acabam sobrevivendo, especialmente por conta da existência de códigos criados pela agenda global. Seu universo é dinâmico e elástico, porquanto “[...] ampliam-se as formas e restringem-se as esperanças quando a suas potencialidades transformadoras" (GOHN, 2012, p. 341).

Eles realizam articulações capazes de conectar o local ao global e vice-versa, uma vez que os movimentos sociais, “[...] em tempos de globalização, adquirem status global, caracterizando-se ao mesmo tempo como produtores e produto da agenda internacional" (DE FAZIO, 2014, p. 351). Além disso, ocupam espaço de extrema importância na arena internacional enquanto "operadores da ampla rede dos atores não-estatais". Localizados em vários Estados, estão interligados e comprometidos conjuntamente por um objetivo comum, e se disseminam em nível global. São autônomos, de modo que sua existência independe da vontade e da concordância dos Estados onde estão inseridos ou que exercem suas ações (OLIVEIRA, 2014, p. 109).

Por fim, os movimentos sociais classificam-se como atores internacionais emergentes, de caráter não-estatal, e exercem um importante papel que não pode mais ser ignorado no atual cenário, uma vez que atuam na demonstração de suas agendas, seus objetivos, interesses e seus canais de interconexão, na busca de mudanças sociais em nível global (DE FAZIO, 2014, p. 323). Dentre seu importante protagonismo, e como se verá, está 
sua inserção num dos debates mais relevantes da atualidade: a crise da democracia contemporânea.

\section{A DEMOCRACIA E SUA CRISE CONTEMPORÂNEA}

O conceito de democracia pode ser estudado a partir dos ideais de Rousseau, que considera não somente uma forma de governo, mas "uma concepção de existência humana que considera o público superior ao privado e que representa um valor moral objetivo que se deve universalizar" (VIEIRA, 1997, p.95). Norberto Bobbio, por sua vez, entende que a democracia constitui o "governo dos muitos, dos mais, da maioria [...] em suma, segundo a própria composição da palavra, como governo do povo, em contraposição ao governo de uns poucos" (BOBBIO, 1993, p. 31).

Rousseau entende que "a democracia não pode ser representada pela mesma razão porque não pode ser alienada; ela consiste, essencialmente, na vontade geral, e a vontade não se representa" (2002, p.125).

De sua designação grega demokratia, o poder do povo emergiu para o nível de palavra-chave da teoria do Estado. Pode ser configurada como um conjunto de regras contraposto a outro, bem como um conjunto de regras normativamente orientado (ROSENFIELD, 2006, p.32).

Para Hans Kelsen, democracia significa "identidade entre governantes e governados, entre sujeito e objeto do poder, governo do povo sobre o povo" (KELSEN, 2000, p. 25). A democracia pode simplesmente ser considerada como uma das técnicas possíveis de produção das normas da ordenação. Kelsen entende, portanto, que a democracia moderna configura "o sistema de produção das normas da ordenação que confia tal tarefa a um corpo (parlamento) eletivo, com a base mais ampla possível (sufrágio universal) e com método eleitoral proporcional (mesmo sem pretensões de representação)" (KELSEN, 1993, p.13).

Fruto de uma série de acontecimentos históricos, a democracia foi marcada por diferentes experiências políticas orientadas geralmente por ideais que envolviam lutas pelo poder e a proteção dos direitos do homem. A noção de democracia expressa, além do exercício do poder pelo povo, o tamanho do território e a densidade populacional, a separação entre a esfera privada e pública, o trabalho, a competição, a cena pública e a mídia (ROSENFIELD, 2006, p.34-36). 
A base do conceito de democracia constitui, sem sombra de dúvidas, a noção de governo do povo que é revelada pela própria etimologia da palavra. Essa concepção advém de ideais gregos, especialmente quanto à afirmação do governo democrático como o governo de todo o povo. A ideia de Estado Democrático de Direito, nessa linha, consolidou-se como um ideal supremo, chegando-se ao ponto que nenhum sistema e nenhum governante, mesmo quando patentemente totalitários, admitem que não sejam democráticos (DALLARI, 2000, p.150).

Nesse particular, pode-se afirmar que a democracia constitui um conceito histórico que não é considerado apenas um 'valor-fim", mas um meio e instrumento da realização de valores essenciais de convivência que se traduzem nos direitos fundamentais da pessoa humana. Não se trata meramente de um conceito político abstrato, mas um processo de afirmação do povo e de garantia dos direitos do homem (SILVA, 2003, p. 125-126).

Tampouco se pode considerar a democracia como um conceito estático, isto é, pronto e acabado. O conceito de democracia não permite que seja transportado ou exportado como um modelo para as imperfeições dos diversos tipos de Estados, uma vez que constitui um processo que implica na busca constante pela evolução. Trata-se, assim, de uma "mutação qualificada pela busca da autodeterminado e liberdade do homem, fruto da contribuição individual de cada qual no produto coletivo, por intermédio da participação política" (DUARTE NETO, 2005, p.25).

A democracia abrange uma síntese de princípios que norteiam os Estados democráticos: em primeiro lugar, a supremacia da vontade popular, que impôs a participação popular no governo, suscitando controvérsias e dando margem a uma série de experiências no que diz respeito à representatividade e à extensão do direito de sufrágio; a preservação da liberdade, entendida como "o poder de fazer tudo o que não incomodasse o próximo e como o poder de dispor de sua pessoa e de seus bens sem a interferência do Estado"; e, por fim, a igualdade de direitos, consistente na proibição de diferenciação no gozo de direitos entre os indivíduos (DALLARI, 2000, p. 151).

Vista como um valor universal, a democracia contribui para aclarar e desenvolver os componentes essenciais do homem, além de ser capaz de promover esse desenvolvimento em diferentes proporções econômicas e sociais. Para Rosenfield, a democracia é "um regime forte, atento à defesa dos seus princípios, e não tolerante em relação a tudo que possa minar os seus fundamentos" (2006, p. 73). 
Existem críticas no sentido de que ainda há uma massa de excluídos que não participam do exercício da soberania popular. Para Coutinho (2000), a verdadeira democracia de "valor universal" somente se efetivará se as massas de excluídos também forem incorporadas ao processo social como autênticos protagonistas participativos. Tem-se, portanto, a necessidade de se permitir que todos os indivíduos tenham a oportunidade de se organizar e de expressar suas opiniões para reivindicar seus pleitos em busca de atingir legitimamente as conquistas sociais, culturais e políticas.

Para Rubio (2014, p.112), a democracia, entendida como o poder do povo, também se camufla com as instituições estatais e representativas, uma vez que "a escolha de representantes pelo povo acaba por tirar-lhe o poder, para somente ser exercido pelo único poder válido: o estatal". Nesse sentido, “a cidadania somente manda simbolicamente, já que, a partir de seu esvaziamento de conteúdo, todo o poder político é outorgado às instituições representativas e do Estado".

Estudado o conceito de democracia, necessário analisar as formas pelas quais a democracia se manifesta. Sob o aspecto político, a democracia pode ser classificada em três formas: democracia direta, democracia indireta ou representativa e democracia semidireta.

Como democracia direta, entende-se aquela em que "o povo exprime a sua vontade exercendo ele próprio as funções do Estado. Quer dizer, tanto a legislação como as principais atribuições executivas e judiciárias são exercidas pelos cidadãos em assembleias populares ou primárias" (SANTANA, 1995, p. 36).

A origem da democracia direta está na Grécia antiga, em Atenas, onde o povo se reunia para o exercício direto e imediato do poder político, transformando a praça pública ou "ágora" no "grande recinto da nação". Nessas reuniões, o povo deliberava sobre questões do Estado "que fazia de sua assembleia um poder concentrado no exercício da plena soberania legislativa, executiva e judicial” (BONAVIDES, 1994, p.268).

Para Ferreira Filho, a democracia direta constitui "uma reminiscência histórica ou uma curiosidade quase que folclórica". Ele considera que, atualmente, a democracia direta não é mais utilizada, e nem é possível adotá-la, face à inviabilidade de reunir milhares de cidadãos para debater os problemas da sociedade (2003, p.81).

Já a democracia indireta ou também entendida como democracia representativa, consiste no exercício do poder pelo povo, que constitui a fonte originária desse poder. Nessa espécie de exercício da democracia, o povo é quem outorga as funções do governo para seus 
representantes, que, de forma indireta em relação ao povo, sejam responsáveis por dirigir as questões públicas de forma direta (BONAVIDES, 2001, p. 64).

Por fim, a democracia semidireta configura uma democracia mista, porque abrange tanto a democracia direta como a democracia indireta. Trata-se, assim, do modelo típico brasileiro, do qual a Constituição Federal prevê mecanismos e garantias que assegurem a soberania do povo. Essa soberania é exercida por meio de instrumentos democráticos, como o plebiscito, o referendo e a iniciativa popular. É uma forma em que há a participação popular, possibilitando ao povo a expressão de sua opinião em determinados assuntos (BONAVIDES, 2001, p. 64).

Atualmente, discute-se a possibilidade de a democracia representativa estar em crise. Entende-se que, embora não seja perfeita, a democracia constitui "um canal adequado de influxo das demandas sociais, sem que isto exclua a (necessária) participação popular" (ALVES e OLIVEIRA, 2015, p.176).

A crise da democracia nos dias atuais configura uma temática complexa composta por muitas variáveis, especialmente em razão da instabilidade da política. É necessário que novos sistemas de democracia sejam eficazes para a participação efetiva e de qualidade do cidadão para o pleno desenvolvimento e exercício da cidadania (KIERECZ, 2016, p.361). Entretanto, e por diversas perspectivas, não pairam dúvidas de que o modelo atual encontra-se sobre forte questionamento na sua efetividade e, em particular, sua legitimidade em relação aos titulares do poder originário: os representados.

Mais do que isso, questiona-se como os movimentos sociais influenciam para a atual crise da democracia, uma vez que "mesmo a oposição entre maiorias e minorias decorrendo logicamente do sistema democrático, não é facultado que determinada maioria decida (ou não decida) sobre tudo, de forma a criar monopólios políticos espúrios" (ALVES e OLIVEIRA, 2015, p.176).

Por conta da conformação do sistema capitalista e em especial do sistema financeiro global, a pressão dos interesses corporativos e as constantes tentativas de resolução de problemas sociais, econômicos e políticos, resta evidenciado que tais aspectos refletem nessa crise. Contudo, a amenização das desigualdades e da exclusão social, bem como a criação de uma política de educação básica séria, estável e duradoura, com o fomento de mecanismos de democracia e a disseminação de uma nova cultura, podem vir a ser uma solução apontada para a crise da democracia (KIERECZ, 2016, p.361). 
Estudado o instituto da democracia, suas formas e a existência de uma crise na democracia contemporânea, passa-se para o estudo do "poder para" como uma categoria instrumental e conceitual.

\section{O "PODER PARA" COMO CATEGORIA INSTRUMENTAL}

O debate envolvendo o poder está diretamente ligado com as relações humanas que se manifestaram ao longo da história. Conceituar o poder configura uma tarefa árdua e complexa, porque o tema fomenta discussões entre diversos estudiosos. O poder constitui, na sua essência, um instrumento de conhecimento em construção ao longo do tempo.

O poder ocupa um importante espaço na esfera política, e é essencial para compreender as relações de domínio, autoridade e governo. Permite examinar os interesses que se encontram ocultos na imposição de vontade e na tomada de decisões. Nesse sentido, o poder configura um conceito fundamental na Ciência Social, da mesma forma em que, na Física, a energia configura esse elemento nuclear (RUSSEL, 1938, p. 4).

A explicação da sociedade está diretamente ligada à questão envolvendo o poder, e é por tal razão que emergiram uma série de debates teóricos sobre o tema, nos mais diferentes períodos, em diversas áreas do conhecimento, tanto por autores clássicos quanto por autores contemporâneos. O debate do poder em evolução até a modernidade integra concepções teóricas que vão desde os escritos de Aristóteles até as concepções de Michel Foucault, Pierre Bourdieu e Michael Mann, por exemplo.

Aristóteles (1996, p. 12) estudava questões relacionadas ao poder em seus escritos, ao definir o homem um "animal político" ao reconhecer a este o poder da fala. Ele afirma que “agora é evidente que o Estado é uma criação da natureza, e que o homem é um animal político. E que aquele que, por natureza ou por mero acidente, está sem um Estado, é um homem mau ou está acima da humanidade".

O poder ainda pode ser encontrado nos estudos de Tomás de Aquino, na sua obra Escritos Políticos. Esse filósofo atenta que o poder se expressa também pela possibilidade de dominação e subordinação. Ele analisou a ideia de que um homem pode exercer domínio sobre outro, e aborda essa questão afirmando que esse "domínio" pode expressar dois sentidos: o primeiro, "é comparado com servidão; e um mestre (Senhor), neste sentido, é aquele para quem alguém é sujeito como escravo"; e o segundo “[...] é entendido como se 
referindo em um sentido geral ao comando de qualquer tipo de sujeito de qualquer forma; e, neste sentido, mesmo aquele que tem a tarefa de governar e dirigir homens livres pode ser chamado de mestre" (AQUINAS, 2002, p. 3-4).

Maquiavel também se dedicou ao estudo do poder, de modo que merecem destaque os escritos realizados na obra $O$ Príncipe. Sua compreensão acerca do que é o poder está diretamente relacionada com o poder político, porque sua obra versa especialmente sobre as formas de adquirir e manter o poder, assim como as virtudes de ser e se tornar um governante. Ele considera que "se um príncipe quiser manter o poder, muitas vezes será forçado a não ser bom”. E ressalta que "[...] quando uma das forças - povo ou soldados ou poderosos que sejam - de cujo apoio o príncipe acredita depender para manter-se é corrupta, convém que ele siga o humor dela a fim de contentá-la, e nesse caso as boas ações lhe serão prejudiciais" (MAQUIAVEL, 1999, p. 83).

Hobbes, por sua vez, estudou o poder com base na sua relação com a natureza humana e pela concepção do Leviatã. Ele considerava que o ser humano possui um desejo perpétuo de deter o poder, e que esse desejo cessa apenas com a morte. Além disso, Hobbes aponta que "[...] o poder de um homem (universalmente considerado) consiste nos meios de que presentemente dispõe para obter qualquer visível bem futuro" (HOBBES, 2009, p. 118).

Nos Tratados de John Locke, também foi possível verificar o debate envolvendo o poder. Para Locke (1967, p. 74), o poder estaria então associado a um direito, ao afirmar que o "poder político deveria ser considerado um direito de produzir as leis". Nesse sentido, o poder político para Locke constitui um verdadeiro estado de sujeição regulado por mecanismos institucionalizados balizadores de sua legitimidade.

Weber, por sua vez, considera que o poder é uma forma de realizar a vontade de um indivíduo mesmo que exista resistência de outrem. Ele ressalta a amplitude do termo poder e da limitação que há na sua análise, e considera que o poder constitui a “[...] probabilidade de que um comando com um determinado conteúdo específico seja obedecido por um determinado grupo de pessoas" (WEBER, 1999, p. 189).

Além desses autores clássicos, diversos autores contemporâneos também se dedicaram ao estudo do poder, justamente por conta da existência das diversas perspectivas a temática abrange. Goverde et al. (2000, p. 5), por exemplo, consideram que o poder é interpretado como um pressuposto, na medida em que os indivíduos atuam e relacionam-se com base em conceitos e pensamentos considerados como pressupostos, pertinentes a uma 
concepção que expressa diferença no ambiente social que se manifesta no dia a dia. Desse modo, “[...] o significado do poder como um conceito ordenador para o estudo da política [...] reside nas suas implicações de que existe um nível muito grande de desarmonia entre os indivíduos e sociedade".

O poder é considerado como um valor instrumental e como algo a ser buscado para obtenção de um resultado específico. Tornou-se, assim, um valor supremo e um fim em si mesmo. Trata-se, logo, de um instrumento fundamental para buscar outros valores, e essa característica faz com que o poder seja visto como uma capacidade de finalidade única para o alcance de determinados desejos e coisas (MOORE, 1972, p. 21).

Também explicando seu entendimento acerca do que é o poder, Giddens parte da ideia primordial de que o poder nem sempre está relacionado a um conflito ou interesse, tampouco é por essência opressivo. Para ele, o "poder é a capacidade de obter resultados" de modo que o fato de tais resultados estarem ou não vinculados a interesses ou conflitos não diz respeito e também não interessam à definição do poder. Ele concebe que o poder exige "estruturas de dominação" pelas quais o poder "flui suavemente em processos de reprodução social" (GIDDENS, 1984, p. 257-258).

Enquanto isso, e para Bourdieu, enfatizando sua dimensão simbólica, o poder é tido como “[...] aquele poder invisível que pode ser exercido somente com a cumplicidade daqueles que não querem saber que eles são sujeitos a ele ou mesmo que eles próprios exercem ele" (1991, p. 164). Sob a ótica de Galbraith (1986, p. 13), o exercício do poder é verificado a partir de uma relação de submissão de um indivíduo a vontade de outrem. Sua manifestação é inevitável no período moderno, uma vez que nada mais é realizado sem a presença do poder. Ele pode ser tanto socialmente perverso, quanto benéfico e imprescindível na sociedade atual.

Também pode ser ainda definido como "[...] aquele poder concreto que todo indivíduo detém e cuja cessão parcial ou total permite ser estabelecido o poder político ou a soberania" (FOUCAULT, 1994, p. 26-27). Essa concepção de poder advém do século XVIII, fundada no contratualismo, e tem como contraponto a opressão. Nesse sentido, Foucault (1994, p.30) complementa que "[...] a concepção de poder como um direito original que é renunciado para o estabelecimento da soberania, e o contrato, como uma matriz do poder político, fornece os seus pontos de articulação". 
Em termos mais amplos, o poder exerce um papel central e de amplo espectro na teoria política e na vida em sociedade, porque configura “[...] o núcleo dos debates em torno da constituição, da representação, da legitimidade e da autoridade de todos os processos que envolvem o manejo de interesses e expectativas da vida social” (OLSSON, 2007, p. 55).

A construção do conceito de poder, por sua vez, deve partir da compreensão contemporânea desse fenômeno, porque o poder retrata relações políticas e sociais que acontecem no mundo da vida. Nesse sentido, pesquisadores contemporâneos que debatem o tema analisam o poder com base em uma classificação tradicional que envolve o "poder para" e o "poder sobre", cujo foco é objeto de estudo no presente artigo.

Essa classificação fundamenta-se na premissa introduzida pioneiramente por Pitkin, no sentido de que o poder é algo exercido "sobre outro ou outros" (poder "sobre") ou, ainda, na capacidade de produzir algo a partir do envolvimento de outras pessoas, mas não necessariamente, como forma de expressão de um poder consensual (poder "para"). A mencionada autora ainda ressalta que '[...] se 'poder' fosse uma etiqueta para certos fenômenos, tal distinção não poderia ser de grande importância, uma vez que as duas expressões necessariamente envolveriam a mesma ideia de poder simplesmente postas em diferentes contextos verbais" (PITKIN, 1972, p. 276).

Como se pode perceber dos diversos conceitos já explicitados, a categoria do "poder sobre" é reconhecida, por exemplo, por Max Weber, teórico que estudou o poder a partir de acepções ideológicas, econômicas e políticas. Para ele, o poder configura a "[...] possibilidade dentro de um relacionamento social, de realizar a vontade de alguém mesmo contra resistência, independentemente da base na qual essa possibilidade se funda" (WEBER, 1999, p. 28).

A concepção de Weber quanto ao "poder sobre" expressa uma clara relação de subordinação de um sobre outro. Abrange, assim, meios de coerção voltados para o cumprimento dos desejos e das vontades dos detentores de poder. Ele parte da ideia de comando e obediência para considerar o "poder sobre", porque afirma que poder configura uma forma de imposição da vontade de alguém sobre outro. Em resumo, trata-se da “[...] possibilidade de um indivíduo ou grupo de realizar sua vontade no contexto de atividade coletiva mesmo contra a resistência de outros envolvidos" (WEBER, 1999, p. 531).

Essa categoria de poder expressa tanto o poder político, quanto o poder militar, de modo que, “[...] de um lado, a política central, incluindo o aparato estatal e (onde eles 
existem) os partidos políticos: de outro lado, força física ou militar” (MANN, 1993, p. 22-28). Por sua vez, os instrumentos de coerção dessa categoria do "poder sobre" são formas de controle coercitivo, nos quais existe uma extensa penumbra “[...] na qual populações aterrorizadas normalmente não vão pisar além de certos detalhes de obediência, mas cujo comportamento não pode ser controlado positivamente" (MANN, 1993, p. 25-27).

Nesse contexto, o "poder sobre" constitui um exercício de autoridade que se impõe sobre outros atores, partindo do de maior poder ao outro, como parte mais fraca dessa relação.

Enquanto que o "poder sobre" tem suas relações inseridas no contexto social, o "poder para" manifesta-se nas "[...] práticas dos atores, podendo a sua potência resultar em um aumento de poder para todos os participantes" (SALLES, 2017, p. 84). Essa categoria de poder configura uma relevante contribuição para a compreensão do poder de forma geral, e seus principais estudos emergem em trabalhos de Talcott Parsons (1967) e Hannah Arendt (1970).

O "poder para" não está relacionado à resistência, dominação, comando ou obediência, mas pertence a instituições políticas e possui caráter agregador (SALLES, 2017, p. 84). Para Hannah Arendt, o poder "corresponde à habilidade humana de não somente agir, mas de agir de forma concertada". Segundo a autora, o “[...] poder nunca é uma propriedade de um indivíduo; ela pertence a um grupo e permanece existindo somente ao longo do tempo em que o grupo permanece unido" (ARENDT, 1970, p. 40). O “poder para" é também concebido por Parsons (1967, p. 306), que entende o define como “[...] a capacidade generalizada de garantir a eficiência de obrigações vinculantes entre unidades em um sistema de organização coletiva quando as obrigações são legitimadas com referência à sua relevância para objetivos coletivos".

A diferença entre ambos, no particular, é mais sutil, porque, enquanto Parsons (1967) admite a existência de um "poder sobre", que corresponde a uma espécie do gênero maior do que ele denomina de "poder para", Arendt (1970) considera que a teoria acerca do "poder para" dá-se no sentido de que este é considerado um verdadeiro poder, enquanto que o "poder sobre" pode ser considerado uma manifestação de violência. De qualquer forma, ambos reconhecem essa específica categoria, e destacam sua grande relevância para a vida em sociedade. 
Assim, tomando por base o conceito de poder e a dissociação entre "poder para" e "poder sobre", pode-se avançar para a análise das possibilidades dos movimentos sociais globais na (re)democratização contemporânea no século XXI.

\section{AS POSSIBILIDADES DOS MOVIMENTOS SOCIAIS GLOBAIS NA (RE)DEMOCRATIZAÇÃO CONTEMPORÂNEA}

A partir dos estudos realizados por Gohn, é possível afirmar que os movimentos sociais sempre existiram em algum tipo de expressão, e é provável que continuem existindo. Eles “[...] representam forças sociais organizadas, aglutinam as pessoas não como força-tarefa de ordem numérica, mas como campo de atividades e experimentação social, e essas atividades são fontes geradores de criatividade e inovações socioculturais" (GOHN, 2011b, p. 336). Os movimentos sociais são considerados importantes figuras na sociedade, entendidos por Mattar (2013, p. 116) como "agentes fundamentais para trazer mudanças dentro das sociedades". São, assim, "manifestações de mudança social”, e apresentam uma estrutura diferenciada, composta por atores, lutas a ações coletivas. Os movimentos sociais “[...] apresentam natureza orgânica e estão mudando e se adaptando constantemente às novas lutas e necessidades sociais" (MATTAR, 2013, p. 119).

Esses atores apresentam um verdadeiro "potencial reformador", uma vez que, segundo De Fazio (2012, p. 75), “[...] as ações desses movimentos no plano global seguem nessa direção, de modo que [...] tratam de consolidar um novo equilíbrio em escala global, de modo a evitar a contínua imposição [...] do pagamento de excessivos custos sociais e ambientais".

Para Castells (2013, p. 161-162), “os movimentos sociais foram e continuam a ser as alavancas da mudança social". Essa mudança exige um agir individual ou coletivo, e que carrega uma série de emoções, assim como qualquer comportamento humano. Na medida em que ocorre o processo de ação comunicativa, que resulta na ação e na mudança social, predomina a emoção do entusiasmo, fazendo com que se reforce ainda mais a mobilização pelos movimentos, superando o medo e outras emoções.

Para Gohn (2013, p. 40-41), os movimentos sociais constituem "elementos e fontes de inovações e mudanças sociais", capazes de mobilizar ideias e valores, bem como de gerar saberes e aprendizado coletivo. Devem ser vistos como "elementos fundamentais na 
sociedade moderna", uma vez que é plenamente reconhecido seu potencial reformador, haja vista serem detentores de um saber inigualável que decorre de suas condutas no cotidiano.

Os movimentos sociais pautam-se em ações reformadoras que " [...] tem lugar em sua política dual, ou seja, defende o mundo da vida contra a colonização pela lógica sistêmica, ao mesmo tempo em que pretende influenciar na política do Estado". A atuação desses movimentos tem como principal objetivo o oferecimento de resistência ao projeto sistêmico estabelecido, de modo que seus propósitos influenciam diretamente na esfera em que as decisões estatais são tomadas, reverberando, inclusive, na democratização contemporânea (DE FAZIO, 2012, p.75).

Os movimentos sociais passaram a ser considerados como "transnacionais" em razão das mudanças ocorridas por conta do intenso desenvolvimento tecnológico, porque “[...] questões locais/nacionais estão agora conectadas com estruturas e problemas globais mais amplos" (MATTAR, 2013, p. 142).

O fenômeno da globalização foi decisivo para que os movimentos sociais se expandissem de tal modo que se tornassem globais, de modo que “[...] a principal conexão entre os movimentos sociais e a globalização neoliberal encontra-se no segundo fenômeno, o qual leva ao desenvolvimento de injustiças e de subsequentes conflitos sociais", o que resulta "no desenvolvimento de novas formas de ativismo e ação coletiva no espaço internacional" (MATTAR, 2013, p. 151).

Os movimentos sociais globais mobilizam recursos no intuito de alcançar seus diversos objetivos, com base em iniciativas que tem como finalidade "consolidar um novo equilíbrio em escala global”. Essas iniciativas consistem em mobilizações, conferências, protestos, marchas e demais ações que dão forma a um movimento social global (DE FAZIO, 2014, p. 353).

Elas são ações globais porque "[...] estão conectados com o mundo inteiro, aprendem com outras experiências, e, de fato, muitas vezes são estimulados por essas experiências a se envolver em sua própria mobilização" (CASTELLS, 2013, p. 165). Essa natureza "global" também se verifica a partir do debate contínuo que os movimentos sociais globais realizam na internet, provocando, inclusive, a participação conjunta e paralela em manifestações mundiais articuladas em rede. Para Castells (2013, p. 165), eles “[...] expressam uma profunda consciência da interligação de questões e problemas da humanidade em geral e exibem claramente uma cultura cosmopolita". 
Além disso, o caráter global dos movimentos sociais se expressa pela expansão transnacional dos alvos de suas lutas, tendo em vista que os protestos e as manifestações se tornaram cada vez mais organizadas, "especialmente por causa do desenvolvimento simultâneo das novas tecnologias" (MATTAR, 2013, p. 142-143).

As manifestações dos movimentos sociais globais na área internacional por meio das redes configuram um processo dominante na sociedade contemporânea informacional, porque atingiu a própria noção de poder neste espaço. O poder, que estava, até então, depositado exclusivamente nas mãos do Estado soberano, com as transformações ocasionadas pelo fenômeno da globalização e pelo desenvolvimento e modificações na sociedade contemporânea, foi agora reconfigurado, e também exercido pelos movimentos sociais globais, em razão de suas ações e manifestações na agenda internacional.

Esse poder é exercido de forma conjunta, isto é, na modalidade do "poder para", uma vez que os movimentos sociais compreendem coletividades que lutam na busca de objetivos comuns. Seu destacado protagonismo se dissemina de forma acentuada, fazendo com que consigam mobilizar recursos para atingir seus objetivos. Eles estabelecem, inclusive, relações com o Estado, tornando-se influentes no poder de decisão dos entes soberanos. É por meio dessas ações que se verifica o exercício do poder por parte desses atores não-estatais.

Desse ponto de vista, é possível afirmar que os movimentos sociais globais exercem "poder para" a partir de suas ações na arena internacional. De modo geral, ocupam-se de lutas por mudanças sociais e de interesse global, como proteção do meio ambiente, combate à corrupção, proteção dos direitos humanos, luta pela igualdade de gênero, ajudas humanitárias, mudanças de um sistema político, dentre outros objetivos. A variedade de propósitos, espaços de atuação e alcance variam, mas seu protagonismo atinge o nível global, sempre com ações concertadas e articuladas.

Nesse viés, os movimentos sociais globais são capazes de exercer poder, porque promovem autêntica governança sem governo, com arregimentação da opinião pública, articulando-se por redes sociais e mobilizando outros atores em torno de suas causas, e não faltam exemplos como o Movimento Primavera Árabe ou o Movimento Ocupe Wall Street. O seu protagonismo, pela expressão em larga escala, impacta outros atores globais.

Assim, os movimentos sociais globais estão peculiarmente conectados com o "poder para", pelo exercício de uma grande marcha de influências perante os demais atores internacionais que fazem parte desse cenário, pela sua presença nos espaços em nível global, 
seja física, seja virtual, conquistando a opinião pública, o que reflete nos limites e possibilidades da democracia contemporânea.

Diferentemente do Estado, os movimentos sociais globais não exercem o "poder sobre" por meio do poder militar ou econômico, isto é, mediante dinheiro, armas e imposição da força. Ao contrário, sua atuação se baseia na reunião de indivíduos que lutam, pressionam e mobilizam a sociedade com o objetivo de alcançarem seus interesses, e esse poder constitui uma expressão concreta da democracia participativa.

O principal traço dos movimentos sociais globais diz respeito à sua condição de atores coletivos conectados por uma agenda comum compartilhada. A partir do momento em que o espaço público passou a ser ocupado pelos movimentos sociais, o Estado tornou-se alvo de reivindicações por parte dos indivíduos. Suas ações constituem o canal de expressão das demandas sociais populares e configuram o exercício direto da democracia por parte dos cidadãos, que, nesses movimentos, externam suas vozes fora dos canais mediados pela tradicional representação parlamentar.

Isso demonstra que a democracia participativa é exercida também pelos movimentos sociais globais. Na medida em que os indivíduos são ouvidos, as deliberações sobre os problemas sociais, o reconhecimento das minorias e a reivindicação de direitos são concretizadas. Assim, as ações dos movimentos sociais marcam, sensivelmente, a consolidação da democracia participativa, contribuindo, inclusive, para o desenvolvimento social.

Verifica-se, assim, que a atuação dos movimentos sociais globais inverte a lógica tradicional do poder político contemporâneo, reconfigurando o poder do Estado nessa perspectiva. Os representantes do povo não mais conseguem identificar e atender a todas as demandas da sociedade, seja por impossibilidade, ou por falta de prioridade. Com isso, a atuação dos movimentos sociais globais e sua participação no espaço público formam a opinião pública, fazendo com que seus objetivos ganhem cada vez mais o poder coletivo. Esse poder é exercido por esses atores mediante protestos, manifestações e mobilizações públicas, ou seja, não o fazem pelos meios do "poder sobre” em que há uma relação de subordinação de um sobre o outro.

Por fim, o exercício desse poder pelos movimentos sociais globais configura a forma mais autentica da democracia do século XXI. É a própria sociedade exercendo o poder sem o 
intermédio de representantes, o que se mostra extremamente importante na atual era, por ser a forma mais legítima da democracia participativa.

\section{CONSIDERAÇÕES FINAIS}

A partir do desenvolvimento do presente estudo, foi possível revelar que os movimentos sociais globais são atores internacionais emergentes de caráter não-estatal e ocupam destacado espaço na arena internacional. A partir do momento em que os Estados deixaram de ser os principais detentores de poder na ordem internacional, com o surgimento dos atores não-estatais, diversas foram as transformações que passaram a ocorrer na estrutura da sociedade internacional, proporcionadas pelo fenômeno da globalização.

Com isso, foi possível verificar que a sociedade internacional é globalizante, e deixou de ser vista no seu sentido meramente estatocêntrico, mas, sim, multicêntrico, na medida em que tem como protagonistas não somente os Estados, mas uma multiplicidade de atores e de fluxos internacionais, como, por exemplo, os movimentos sociais globais.

Foi possível verificar que, atualmente, a democracia encontra-se em uma verdadeira crise contemporânea, especialmente pela instabilidade política dos Estados. Nesse viés, os movimentos sociais ocupam espaço de extrema importância nesse cenário, por conta do poder que possuem para influenciar a opinião pública e atingir seus objetivos, de acordo com seus interesses comuns.

Ainda, tornou-se evidente que poder incorpora-se na vida em sociedade e está integralizado diretamente nas relações humanas ao longo do tempo. Trata-se de um elemento essencial para a compreensão da política e das relações sociais, assim como as possibilidades e os limites da convivência humana em sociedade. Além disso, verificou-se que o poder pode ser exercido de várias formas, em especial, de forma conjunta, em rede e diretamente relacionado com a comunidade, como no caso dos movimentos sociais globais.

Assim, o "poder para" dos movimentos sociais globais é exercido por conta de seu relevante potencial reformador que se manifesta por meio de suas ações que reconfiguram a sociedade internacional contemporânea. Diferentemente dos Estados, que exercem o "poder sobre", na relação de subordinação e uso da força, com o weberiano monopólio da violência legítima, os movimentos sociais globais são atores coletivos que exercem poder sem 
intermediários e constituem a expressão da democracia participativa, e interferem nas decisões dos Estados.

É possível, portanto, considerar que os movimentos sociais globais são caracterizados principalmente pelo específico poder do qual são detentores, de modo que isso resulta em grandes reflexos no cenário internacional em razão da autonomia e da influência que exercem. Por fim, conclui-se que a sociedade internacional está marcada pelo protagonismo dos movimentos sociais globais em razão do seu "poder para", sendo inegável o espaço que ocupam neste momento histórico.

\section{REFERÊNCIAS}

ALVES, Fernando de Brito; OLIVEIRA, Guilherme Fonseca de. "Crise" da democracia representativa e a função política do Judiciário: é o Judiciário a "tábua de salvação" da democracia? Revista do Programa de Pós-Graduação em Direito da UFC., 2015. p.165-179.

AQUINAS, St. Thomas. Political writings. Edited and translated by R. W. Dyson. Cambridge: Cambridge University Press, 2002.

ARENAL, Celestino del. La teoría de las relaciones internacionales. Madrid: Tecnos, 1979.

ARENDT, Hannah. On violence. New York: Harcourt, Brace \& World, 1970.

ARISTÓTELES. The politics and the constitution of Athens. Edited by Stephen Everson. Revised student edition. Cambridge: Cambridge University Press, 1996.

BARBÉ, Esther. Relaciones internacionales. Madrid: Tecnos, 1995.

BEDIN, Gilmar Antônio. A sociedade internacional e o século XXI: em busca da construção de uma ordem judicial justa e solidária. Ijuí: Ed. Unijuí, 2001.

BOBBIO, Norberto. Liberalismo e democracia. São Paulo: Editora Brasiliense, 1993.

BONAVIDES, Paulo. Teoria Constitucional da Democracia Participativa: por um direito constitucional de luta e resistência, por uma nova hermenêutica, por uma repolitização da legitimidade. São Paulo: Editora Malheiros, 2001.

Ciência política. 10a ed. São Paulo: Malheiros, 1994.

BRANDL, Kamila Soraia; DE FAZIO, Marcia Cristina Puydinger de. O protagonismo dos governos não centrais nas Relações Internacionais: as experiências do Quebec como ator não estatal. In: OLIVEIRA, Odete Maria de (Org.). Relações internacionais, direito e poder: o contraponto entre os atores estatais e não estatais. Ijuí: Ed. Unijuí, 2015. p. 221-258.

BOURDIEU, Pierre. Language and symbolic power. Edited and introduced by John B. Thompson. Translated by Gino Raymond and Matthew Adamson. Oxford: Polity Press, 1991. 
CASTELLS, Manuel. Redes de indignação e esperança: movimentos sociais na era da internet. Tradução Carlos Alberto Medeiros. 1. ed. Rio de Janeiro: Zahar, 2013.

COUTINHO, Carlos Nelson. Contra a corrente: ensaios sobre democracia e socialismo. São Paulo: Cortéz, 2000.

DE FAZIO, Marcia Cristina Puydinger. A sociedade civil global e a rede: resistência à globalização desde cima? Ijuí: Ed. Unijuí, 2012.

Protagonismos e cenários dos movimentos sociais globais: atores não estatais de resistência e o poder das redes. In: OLIVEIRA, Odete Maria de (Org.). Relações internacionais, direito e poder: cenários e protagonismos dos atores não estatais. Ijuí: Ed. Unijuí, 2014. v. I. p. 323-364.

DALLARI, Dalmo de Abreu. Elementos de teoria geral do Estado. 21 ed. São Paulo: Saraiva, 2000.

DOWBOR, Ladislau. A reprodução social. Petrópolis: Vozes, 2002.

DUARTE NETO, José. Iniciativa popular na constituição federal. São Paulo: RT, 2005.

FERREIRA FILHO, Manoel Gonçalves. Curso de Direito Constitucional. 30. ed., rev. e atual. São Paulo: Saraiva, 2003.

FOUCAULT, Michel. Two Lectures. In: KELLY, Michael (Ed.). Critique and power: recasting the Foucault/Habermas debate. Cambridge: The MIT Press, 1994. p. 214-256.

GALBRAITH, John Kenneth. Anatomia do poder. Tradução Hilário Torloni. 2. ed. São Paulo: Pioneira, 1986.

GIDDENS, Anthony. As consequências da modernidade. Tradução Raul Fiker. 2. ed. São Paulo: Editora da Unesp, 1991.

GOHN, Maria da Glória. Movimentos sociais e redes de mobilizações civis no Brasil contemporâneo. 7. ed. Petrópolis: Vozes, 2013.

Teorias dos movimentos sociais: paradigmas clássicos e contemporâneos. 10. ed. São Paulo: Loyola, 2012.

Movimentos sociais na contemporaneidade. Revista Brasileira de Educação, Rio de Janeiro, v. 16, n. 47, p. 333-362, maio-ago. 2011b. Disponível em: <http://dx.doi.org/10.1590/S1413-24782011000200005>. Acesso em: 7 nov. 2017.

Movimentos sociais no início do século XXI: antigos e novos atores sociais.

Petrópolis: Vozes, 2003. 
GOVERDE, Henri et al. (Eds.). Power in contemporary politics: theories, practives, globalizations. London: Sage, 2000.

HALL, Stuart. A identidade cultural na pós-modernidade. Tradução Tomaz Tadeu da Silva e Guacira Lopes Louro. 3. ed. Rio de Janeiro: DP\&A, 1999.

HOBBES, Thomas. Leviatã ou a matéria, forma e poder de um Estado eclesiástico e civil. Tradução João Paulo Monteiro e Maria Beatriz Nizza da Silva. 4. ed. São Paulo: Nova Cultural, 1988. v. I e II.

KELSEN, Hans. A democracia. Tradução Vera Barkow. São Paulo: Martins Fontes, 1993.

KIERECZ, Marlon Silvestre. A crise da democracia representativa no Brasil. Cadernos do Programa de Pós-Graduação em Direito da UFRGS. Porto Alegre. vol XI, número 2, 2016, p. 360-385.

LOCKE, John. Two treatises of government. 2nd ed. Critical edition with na introduction and apparatus criticus by Peter Laslett. Cambridge: Cambridge University Press, 1967.

MANN, Michael. The sources of social power. Cambridge: Cambridge University Press, 1993.

MAQUIAVEL, Nicolau. O príncipe. Tradução Olívia Bauduh. São Paulo: Nova Cultural, 1999.

MATTAR, Khris. O movimento de justiça global: uma nova mobilização política de resistência? Ijuí: Ed. Unijuí, 2013.

McLUHAN, Marshall. Os meios de comunicação como extensão do homem. Tradução Décio Pignatari. 5. ed. São Paulo: Cultrix, 2001.

MERLE, Marcel. Sociologia das relações internacionais. Tradução Ivonne Jean. Brasília: UnB, 1981.

MOORE, Barrington. Poder político e teoria social: sete estudos. São Paulo: Cultrix, 1972.

OLIVEIRA, Odete Maria de. Relações internacionais, direito e atores não estatais: delineamentos de fundamentação. In: OLIVEIRA, Odete Maria de. (Org.). Relações internacionais, direito e poder: cenários e protagonismos dos atores não estatais. Ijuí: Ed. Unijuí, 2014. v. I. p. 33-131.

Relações Internacionais: breves apontamentos e contextualização. In: OLIVEIRA, Odete Maria de (Coord.). Relações internacionais \& globalização: grandes desafios. 2. ed. Ijuí: Ed. Unijuí, 1999. p. 15-66.

OLSSON, Giovanni. Poder político e sociedade internacional contemporânea: governança global com e sem governo e seus desafios e possibilidades. Ijuí: Ed. Unijuí, 2007. 
PITKIN, Hanna Fenichel. Wittgenstein and justice: on the significance of Ludwig Wittgenstein for social and political thought. Berkeley: University of California Press, 1972.

REYNALDO, Renata Guimarães. O protagonismo da Marcha Mundial das Mulheres: a era da informação, novas tecnologias e a rede. In: OLIVEIRA, Odete Maria de (Org.). Relações Internacionais, direito e poder: atores não estatais na era da rede global. Ijuí: Ed. Unijuí, 2016. p. 261-282.

ROSENFIELD, Denis Lerrer. A democracia ameaçada: o MST, o teológico-político e a liberdade. Rio de Janeiro: Topbooks, 2006.

ROUSSEAU, Jean Jaques. Do Contrato Social. Trad. J. Cretella Jr. E Agnes Cretella. São Paul: Editora Revista dos Tribunais, 2002.

RUBIO, David Sanchez. Encantos e desencantos dos direitos humanos: de emancipações, libertações e dominações. Tradução Ivone Fernandes Morcilho Lixa, Helena Henkin. Porto Alegre: Livraria do Advogado, 2014.

RUSSEL, Bertrand. Power: a new social analysis. London: George Allen \& Unwin, 1938.

SALLES, Eduardo Baldissera Carvalho. A sociedade global e os atores não estatais: o poder das corporações transnacionais. 2017. 130 f. Dissertação (Mestrado em Direito) - Programa de Pós-Graduação em Direito, Universidade Comunitária da Região de Chapecó, Chapecó, 2017.

SANTANA, Jair Eduardo. Democracia e cidadania: o referendo como instrumento de participação política. Belo Horizonte: Del Rey, 1995.

SILVA, José Afonso da. Curso de Direito Constitucional Positivo. 22. ed. rev. e atual. São Paulo: Editora Malheiros, 2003.

VIEIRA, Luiz Vicente. A democracia em Rousseau: a recusa dos pressupostos liberais. Porto Alegre: EDIPUCRS, 1997.

WEBER, Max. Economia e sociedade: fundamentos da sociologia compreensiva. Tradução Regis Barbosa e Karen Elsabe Barbosa; Revisão técnica de Gabriel Cohn. Brasília: UnB, 1999. 